\title{
THE RATE OF EVAPORATION OF PARTICLES IN SOME PESTICIDE AEROSOLS
}

\author{
By E. O. POWELL ANd T. W. PEARCE \\ The Microbiological Research Department, Ministry of Supply, \\ Porton, Wiltshire
}

(With Plate 14 and 2 Figures in the Text)

INTRODUCTION

A number of the highly active modern-agents for the control of various pests are applied in the form of aerosols, made either by spraying solutions or emulsions, or by heat volatilization. A knowledge of the physical properties of the aerosol particles - in particular, of their rate of evaporation - is of value, in conjunction with pharmacological data, in assessing the dosage appropriate to given circumstances. The agents concerned are organic substances of high boiling-point, and individual particles of a few microns diameter may require from some seconds to some hours to evaporate completely.

We give here the evaporation rates of particles of some of the substances in common use as aerosols, viz. a germicide, 4- $n$-hexyl-1:3-resorcinol (' $\mathrm{HR}$ '); insecticides, 1, 1, 1-trichloro-2, 2-di ( $p$-chlorphenyl)-ethane ('DDT'), $\gamma$-hexachlorocyclo-hexane ('BHC', 'Lindane', 'Gammexane'), and 'Dieldrin',

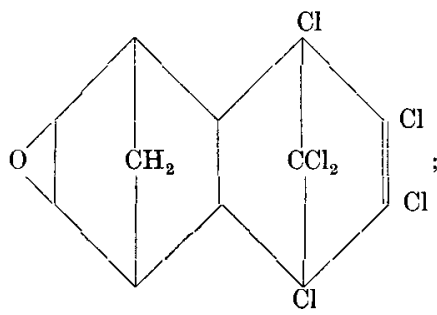

and an acaricide, azobenzene. For comparison with DDT, some results on its $o p^{\prime}$ isomer are included. Our measurements do not overlap with evaporation rates as ordinarily determined, since in aerosols the particles are almost always supercooled liquids, and their vapour pressure is several times that of the stable, i.e. solid, form at the same temperature.

\section{EXPERIMENTAL METHOD}

The method used to determine evaporation rates of aerosol particles was that due in the main to Whytlaw-Gray and his colleagues (Whytlaw-Gray \& Patterson, 1932), involving the use of a slit ultra-microscope specially adapted to work of this kind (Twort, Baker, Finn \& Powell, 1940).

A small sample of aerosol is sucked into the microscope cell, and the velocity of fall of a selected particle is measured by timing its transit between cross-wires in the 
eyepiece of the microscope. The particle is then restored to its former level, and kept in view by displacing the contents of the cell upwards by means of a screw. After a convenient time (up to 1 min., depending on the rate of evaporation) the transit is re-measured, and this process repeated until a considerable reduction in the size of the particle has occurred. The evaporation rate can then be determined from the rate of change of fall velocity.

Further details of procedure and instrumentation are given by Twort et al. (1940). The ultra-microscope employed in the present experiments was similar to the one described by them, but a number of refinements were introduced:

(i) The microscope was housed in a room, the temperature of which was maintained constant within about $\pm 1^{\circ} \mathrm{C}$.

(ii) A universal mounting enabled the microscope cell (Pl. 14, $A$ and Text-fig. 1) to be tilted about two horizontal axes intersecting in the centre of the working volume, one parallel to the microscope body, one to the illuminating beam $(B, C)$. The aerosol particles fall vertically under gravity, but they are displaced upwards along a line parallel to the cell axis. If these two directions do not coincide, a progressive lateral displacement occurs during the course of an experiment. Normally, therefore, the cell should be strictly vertical, but any appreciable horizontal shift in the position of a particle due to Brownian motion can be counteracted by an appropriate temporary tilt. Observations on a single particle can thus be prolonged indefinitely.

(iii) The cell was connected by a short piece of soft rubber tubing at its lower end to a tap $(\mathrm{Pl} .14, D)$ and thence via a charcoal filter $(E)$ to the displacing screws $(G)$. The tap was closed on every occasion of a velocity determination and, by shortening the column of air in which the particles were suspended, made their motion much less sensitive to disturbance by transient changes of pressure and temperature.

(iv) The lower part of the cell was filled with granular absorbent charcoal, and a tube of charcoal closed by gauze was inserted into its upper part after a sample had been sucked into the working space (Text-fig. 1). This precaution ensured that the particles would evaporate as if into an infinite atmosphere (so meeting the requirements of the simple theory discussed below) and that the air supplied from the displacing screws would be free from condensible vapours. The charcoal was replaced and the cell washed out with acetone at frequent intervals.

(v) Since only relatively large particles were examined (radius $>0.3 \mu$ ) a strong illuminant was unnecessary. A $50 \mathrm{~W}$., $8 \mathrm{~V}$. tungsten lamp was found sufficient, and with this light source it was calculated that the rise in temperature of an illuminated particle would certainly be less than $0 \cdot 1^{\circ} \mathrm{C}$.

The aerosols were made either by atomizing concentrated solutions in a variety of pure volatile organic solvents or by, cooling the vapour from a heated cup of the molten substance. At least two different solutions of each substance were used in order to detect any anomalies due to chemical association or to change in state of aggregation. With one simply explained exception, no such anomalies were found, and the experimental variation appeared to be independent of the method of producing the particles and of their sizes. The particles selected for measurement 
were among the largest present in the sample to which they belonged; because of their higher fall velocity they soon became widely separated from their neighbours, so that their evaporation was unimpeded.

Measurements on particles of the less volatile substances were discontinued before the radius had fallen to half its initial value. Involatile impurities were then not concentrated sufficiently to lower the vapour pressure by a significant amount. Azobenzene and $\mathrm{BHC}$ evaporated so rapidly that this restriction had to be relaxed. In order to obtain a useful number of fall velocity measurements on any one particle, determinations were repeated as quickly as possible until the particle had evaporated to about one-fifth of its initial radius.

The extreme range of radii of the particles measured was from $2 \cdot 5 \mu$ (largest initial radius) to $0 \cdot 3 \mu$ (smallest final radius), corresponding to a range of fall velocity of from 1000 to $20 \mu /$ sec.

\section{VALIDITY OF THE METHOD}

It is desirable that the results should be used to calculate, for each substance examined, a characteristic constant. The constant here chosen is the product $D p_{0}$ of the diffusion coefficient $D$ of the vapour and the saturated vapour pressure $p_{0}$, to which evaporation rate is proportional. It is therefore necessary to consider whether the experimental arrangement is such as to yield numerical results of general validity.

Langmuir's (1918) law for the evaporation of a sphere reads

or

$$
\begin{gathered}
-\frac{d m}{d t}=\frac{4 \pi D M p_{0} r}{R T}, \\
-\frac{d r}{d t}=\frac{D M p_{0}}{R T \rho r}
\end{gathered}
$$

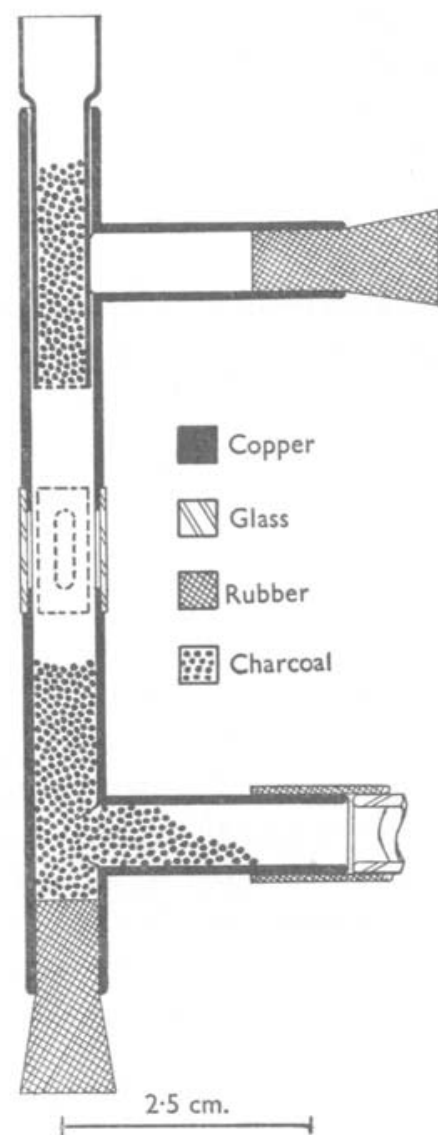

Text-fig. 1. Ultra-microscope cell, section normal to axis of microscope. Position of observation window shown dotted.

in which $t=$ time, $m=$ mass of particle, $M=$ molecular weight of its vapour, $\rho=$ its density, $r=$ its radius, $R=$ gas constant $=8.31 \times 10^{7} \mathrm{ergs} /{ }^{\circ} \mathrm{C}$., $T=$ absolute temperature. Strictly it applies, contradictorily, to a motionless particle of fixed size evaporating into an infinite atmosphere, after a time long enough for a steady state to have been reached; it also ignores the fall in temperature of the particle produced by the evaporation, and the change in vapour pressure over highly curved and electrically charged surfaces. In fact, Whytlaw-Gray \& Patterson's (1932) discussion shows that these latter effects are negligible in particles of the low vapour pressure and of the size range with which we are concerned; and many 
investigators have found that Langmuir's law is obeyed with some accuracy as regards its form. We wish, therefore, to adduce considerations which indicate that the law will also be true as regards the magnitude of its coefficient-that the violation of the conditions of fixed size, infinite atmosphere, and steady state will produce negligible divergence from the ideal.

First, for the ideal particle a steady rate of evaporation is closely approached after any disturbance in a time which makes

$$
\sqrt{ }(\pi D t) \gg r
$$

(This inequality can be deduced from the solution of the analogous problem in heat conduction. See, for instance, Carslaw \& Jaeger, 1947.) For the largest of our particles $(2 \cdot 5 \mu)$ the inequality will be true when $t>10^{-4}$ sec. The real particle is changing in size; the smallest and most volatile of our particles (azobenzene, $0 \cdot 3 \mu$ ) would do so at a rate

$$
-\frac{1}{r} \frac{d r}{d t}=0 \cdot 2 \text { sec. }^{-1}
$$

Thus in $10^{-4}$ sec. the radius would change by $0.002 \%$ only. Clearly, then, the rate of evaporation cannot on this account, and under the least favourable conditions, deviate appreciably from that given by Eqn. 1.

Secondly, if a particle instead of evaporating into an infinite atmosphere is situated near the centre of an enclosure with absorbing walls, the evaporation rate will be increased by an amount of the order of $r / s$, where $s$ is the linear dimension of the enclosure. In the ultramicroscope cell, $s$ is some thousands of times as great as $r$, and the increase is about $0 \cdot 1 \%$, which is much below the experimental error. The glass and metal walls of the cell are themselves capable of absorbing about $10^{-7} \mathrm{~g}$. of vapour - that is, the mass of several thousand aerosol particles - and the charcoal packing is an additional insurance against an accumulation of vapour. Therefore there can, on the other hand, be no restriction of evaporation.

Thirdly, the fall of a particle under gravity must distort the spherical symmetry of the vapour concentration gradient around it. The lower surface is presented to fresh air, the upper to air contaminated with its own vapour. The general theory of diffusion suggests that the rate of evaporation is thereby increased. But the average velocity of recession of vapour molecules from the particle is readily calculated to be $D / s$ at a distance $s$ from its centre (provided that $s$ is not so small that the ratio $D / s$ approaches the velocity of the individual molecules). The velocity of fall of our largest particle $(2 \cdot 5 \mu)$ is about $1 \mathrm{~mm}$./ sec.; at a distance of 100 radii, the value of $D / s$ is about $5 \mathrm{~mm}$./sec. Thus the field of diffusion is not distorted by the particle's motion except at distances too great to have any sensible effect on the rate of evaporation.

On these counts Langmuir's law may be taken as quantitatively true for aerosol particles in the ultra-microscope cell. But it is possible that the value of $p_{0}$ effective in evaporation is less than the saturated vapour pressure as determined by a static method-discrepancies of this kind are known, for instance, in the evaporation of mercury and paraffin oil. 


\section{RESULTS}

With the exception of dieldrin, all the substances measured yielded aerosols of supercooled liquid droplets, as was shown by allowing them to sediment on clean microscope slides. About $90 \%$ of dieldrin particles were solid. Measurements on dieldrin gave two values for the rate of change of fall velocity; many liquid particles crystallized during observation and few runs of useful length could be obtained. Although the solid particles were of a compact shape, they exhibited greater variability in evaporation rate than did liquid droplets.

From ten to twenty runs were made for each substance, usually at $25^{\circ}$ and at $19^{\circ} \mathrm{C}$.

The crude experimental results were treated by the method of Finn \& Powell (1942), i.e. the measured velocities of fall $(V)$ were modified by deducting a correction $(\Delta V)$ to give fictitious velocities $\left(V_{M I}\right)$ obeying Stokes's law in its simplest form, without the Cunningham term

$$
\begin{gathered}
V_{M}=\frac{2 g r^{2} \rho}{9 \eta}, \\
\Delta V=V-V_{M I}=A L \sqrt{ }\left\{V_{M I} \frac{2 g \rho}{9 \eta}\right\},
\end{gathered}
$$

in which $g=$ acceleration of gravity, $\rho=$ density of particle, $\eta=$ viscosity of air, $A=$ Cunningham constant, $L=$ mean free path in gas. In this and subsequent calculations $\rho$ was taken as the density of the solid substance, that of the supercooled liquid being unknown; no great uncertainty arises therefrom at this point, since the correction $\Delta V$, involving $\downarrow \downarrow \rho$, is small. Then, ceteris paribus,

$$
\frac{d V_{M I}}{d t} \propto \frac{r d r}{d t}=\text { constant }
$$

by Eqn. 1. Graphical plots of $V_{M}$ against time were in all cases linear within the experimental error, and there was no evidence of systematic curvature (Text-fig. 2). The value of $d V_{Y} / d t$ for each particle was obtained either by the method of least squares, or, where thirty or more observations had been taken, by Jeffreys's (1939) simplified procedure. These values were then corrected to an atmospheric pressure of 1000 millibars $(750 \mathrm{~mm}$. $\mathrm{Hg}$. very nearly); the diffusion coefficient of a vapour is approximately inversely proportional to the total pressure, but no other factor is appreciably affected. The coefficient of variation of the corrected values was usually less than $10 \%$, much of which was due to temperature differences between runs, vapour pressure in particular being highly sensitive to temperature. Since in any group of runs the temperature range was small $\left(<2^{\circ} \mathrm{C}\right.$.), it was sufficient to consider the factors $p_{0}, D$ and $\eta$ as varying linearly, and to take the mean value of $d V_{M} / d t$ as an unbiased estimate of the true value at the mean temperature.

The products $D p_{0}$ were then calculated from the equation

$$
D p_{0}=-\frac{9 \eta R T}{4 g M} \frac{d V_{M I}}{d t}
$$

obtained by differentiating Eqn. 2 and substituting for $d r / d t$ from Eqn. 1 (Table 1). 
Eqn. 3 does not contain $\rho$, and so $D p_{0}$ is not in doubt except in so far as $\rho$ enters the small correction term $\Delta V$; an error of $50 \%$ in $\rho$ would change $D p_{0}$ by less than its experimental uncertainty.

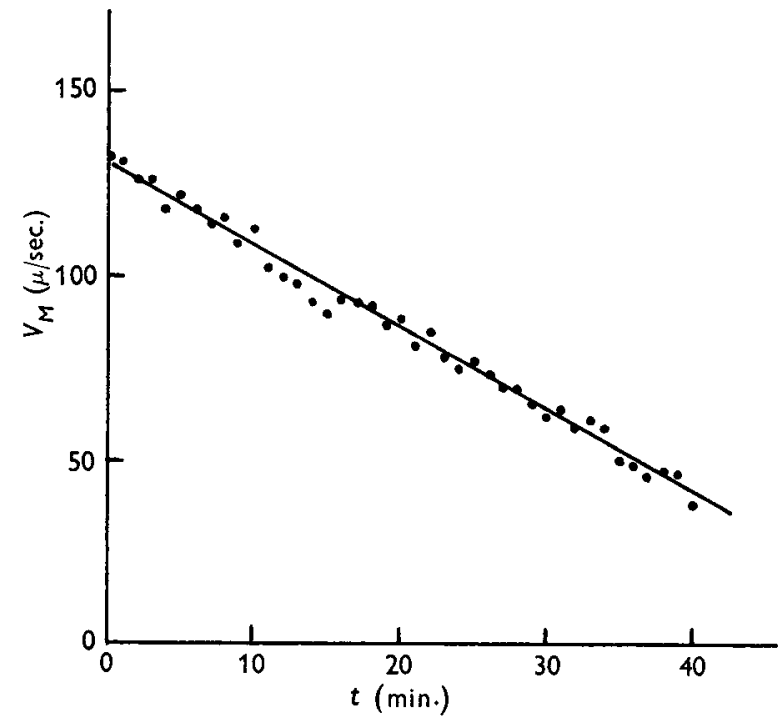

Text-fig. 2. Evaporation of a droplet of DDT initially about $1 \mu$ in radus.

Plot of the modified fall velocity $\left(V_{M}\right)$ against age of droplet, $(t)$.

Table 1. The rate of change of modified fall velocity $d V_{M} / d t$ and the product of diffusion coefficient and vapour pressure $\mathrm{D} p_{0}$, for aerosol particles at an atmospheric pressure of $1000 \mathrm{mb}$.

\begin{tabular}{|c|c|c|c|c|c|}
\hline Substance & $\begin{array}{c}\text { State of } \\
\text { aggregation }\end{array}$ & $\begin{array}{c}\text { Mean } \\
\text { temperature } \\
\left(^{\circ} \mathrm{C} .\right)\end{array}$ & $\begin{array}{l}-d \mathrm{r}_{M} / d t \\
\left(\mu / \mathrm{sec}^{2}\right)\end{array}$ & $\begin{array}{c}\text { Standard } \\
\text { error of } \\
d V_{M} / d t\end{array}$ & $\begin{array}{c}D p_{0} \\
\text { (dynes/sec.) }\end{array}$ \\
\hline Azobenzene & Liquid & $18 \cdot 6$ & $12 \cdot 7$ & $0 \cdot 3$ & $6.97 \times 10^{-2}$ \\
\hline $\mathrm{BHC}$ & Liquid & $18 \cdot 6$ & $2 \cdot 84$ & 0.05 & $9.70 \times 10^{-3}$ \\
\hline $\mathrm{BHC}$ & Liquid & $24 \cdot 7$ & 6.05 & 0.06 & $2 \cdot 15 \times 10^{-2}$ \\
\hline $\mathrm{DD}^{\prime} \mathrm{T}$ & Liquid & $18 \cdot 8$ & 0.0158 & 0.0006 & $4.47 \times 10^{-5}$ \\
\hline DDT & Liquid & $24 \cdot 7$ & 0.0381 & 0.0004 & $1.12 \times 10^{-4}$ \\
\hline$o p^{\prime}-\mathrm{DDT}$ & Liquid & $24 \cdot 9$ & $0 \cdot 105$ & 0.002 & $3 \cdot 10 \times 10^{-4}$ \\
\hline HR & Liquid & $18 \cdot 8$ & 0.0265 & 0.0007 & $1 \cdot 37 \times 10^{-4}$ \\
\hline HR & Liquid & $24 \cdot 8$ & 0.0640 & 0.0005 & $3.43 \times 10^{-4}$ \\
\hline Dieldrin & Liquid & $18 \cdot 6$ & 0.212 & 0.003 & $5.57 \times 10^{-4}$ \\
\hline Dieldrin & Liquid & $25 \cdot 0$ & $0 \cdot 460$ & 0.012 & $1.26 \times 10^{-3}$ \\
\hline Dieldrin & Solid & $18 \cdot 9$ & 0.0349 & 0.0008 & $9 \cdot 18 \times 10^{-5}$ \\
\hline Dieldrin & Solid & $24 \cdot 9$ & $0 \cdot 0819$ & 0.0029 & $2 \cdot 24 \times 10^{-4}$ \\
\hline
\end{tabular}

The quantity $D p_{0}$ is of little immediate appeal, and in much practical work what is required is a rough knowledge of the time $t_{0}$ taken by a particle of known initial radius $r_{0}$ to evaporate completely. Langmuir's law (Eqn. 1 ) is sufficiently accurate for the present purpose, though as Bradley, Evans \& Whytlaw-Gray (1946) have shown, it underestimates $t_{0}$, since there is a finite upper limit to the rate of evaporation at a given temperature (Eqn. 1 makes $-d r / d t \rightarrow \infty$ as $r \rightarrow 0$ ). 
By integration of Eqn. 1 we find

$$
t_{0}=\frac{R T \rho}{2 D M p_{0}} r_{0}^{2}
$$

$t_{0}$ varies with temperature through the factors $T, D$ and $p_{0}$. The last obeys a law of the form

$$
p_{0}=C \exp (-B / T),
$$

and the diffusion coefficient is approximately proportional to $T^{2}$. Hence we may write

$$
D p_{0}=A T^{2} \exp (-B / T) .
$$

From a knowledge of $D p_{0}$ at two temperatures, therefore, the constants $A$ and $B$ can be found. Their values for HR, DDT, BHC and dieldrin were worked out and used to estimate the times of evaporation, at several temperatures, of particles initially $1 \mu$ in radius (Table 2). (For other initial radii the times will be altered

Table 2. Approximate times of evaporation (in seconds) of particles of initial radius $1 \mu$ at the temperatures shown

$\begin{array}{lccccc}\text { Substance } & \begin{array}{c}\text { State of } \\ \text { aggregation }\end{array} & 15^{\circ} \mathrm{C} . & 20^{\circ} \mathrm{C} . & 25^{\circ} \mathrm{C} . & 30^{\circ} \mathrm{C} \text {. } \\ \text { Azobenzene } & \text { Liquid } & - & 10^{*} & - & - \\ \text { BHC } & \text { Liquid } & 129 & 67 & 36 & 19 \\ \text { DDT } & \text { Liquid } & 22,000 & 9,900 & 4,700 & 2,300 \\ \text { op'-DDT } & \text { Liquid } & - & - & 1,700^{*} & - \\ \text { HR } & \text { Liquid } & 10,000 & 4,700 & 2,300 & 1,100 \\ \text { Dieldrin } & \text { Liquid } & 1,600 & 840 & 460 & 250 \\ \text { Dieldrin } & \text { Solid } & 11,000 & 5,100 & 2,500 & 1,300\end{array}$

* Measurements were made at one nominal temperature only; these values are estimated from the regression of $d V_{M} / d t$ within a small temperature range.

approximately in proportion to their squares.) Apart from the failure of Langmuir's law at very small radii, these calculations are subject to error because of the uncertainty in the density, $\rho$, of the supercooled liquid (Eqn. 4); moreover, in commercial samples the presence of impurities, increasing in concentration as evaporation proceeds, will lower the vapour pressure and so prolong the time of evaporation. It is therefore pointless to attempt precise estimates of $t_{0}$; however, a few calculations based on the equation of Bradley et al. (1946) suggest that the figures in Table 2 may be in defect by $10-20 \%$.

The high rates of evaporation of $\mathrm{BHC}$ and azobenzene are noteworthy. They show that aerosols of these substances cannot long persist at low concentrations, and their action must be ascribed principally to direct absorption of vapour or to contact after deposition on solid surfaces.

\section{SUMMARY}

The evaporation rates of small particles in aerosols of the following substances have been measured: 4- $n$-hexyl-1:3-resorcinol, 1, 1, 1-trichloro-2, 2-di ( $p$-chlorphenyl)ethane ('DDT'), 1, 1, 1-trichloro-2-p-chlorphenyl-2-o-chlorphenyl-ethane 
('op'-DDT'), $\gamma$-hexachloro-cyclo-hexane ('BHC', 'Lindane', 'Gammexane'), 'Dieldrin' and azobenzene.

The slit ultra-microscope method was used; a consideration of the experimental conditions leads to the conclusion that the results are of reliable quantitative significance.

The ultra-microscope was constructed by $\mathrm{G}$. Clement, who was also responsible for some features of its design. Much of the computation was carried out by R. Ash. We are also indebted to Messrs Shepherd's Aerosols, Goring-on-Thames, and to Dr P. Bracey, Colonial Office Research Unit, for pure samples of the substances used, and to Mr H. L. Green for some corrections and criticism. Publication is by permission of the Chief Scientist, Ministry of Supply.

\section{REFERENCES}

Bradley, R. S., Evans, M. G. \& WhytlaW-Gray, R. W. (1946). The rate of evaporation of droplets. Evaporation and diffusion coefficients and vapour pressures of dibutyl phthalate and butyl stearate. Proc. roy. Soc. A, 186, 368-90.

Carstaw, H. S. \& Jafger, J. C. (1947). Conduction of heat in solids, lst ed. $386+\mathrm{v}$ pp., 51 text-figs. Oxford: The University Press.

Fins, S. R. \& Powelr, E. O. (1942). The Chemical and physical investigation of germicidal aerosols. I. Germicidal smokes. J. Hyg., Camb., 41, 473-88.

Jefrreys, H. (1939). The Theory of Probability, Ist ed. $380+$ vi pp. (see p. 165). Oxford: The University Press.

LangmuIr, I. (1918). The evaporation of small spheres. Phys. Rev. (2), 12, 368-70.

Twort, C. C., Baker, A. H., Finn, S. R. \& Powell, E. O. (1940). The disinfection of closed atmospheres with germicidal aerosols. J. Hyg., Camb., 40, 254-344.

Whytlaw-Gray, R. \& Patterson, H. S. (1932). Smoke. 192 + viii pp., 12 plates, 33 textfigs. London: Edward Arnold and Co.

\section{EXPLANATION OF PLATE I4}

Slit ultra-microscope for determination of evaporation rates. A, cell of copper tubing (cf. Text-fig. 1); $B, C$, screws for tilting cell; $D$, tap for isolating cell; $E$, charcoal filter; $F$, illuminating system; $G$, displacing screws.

(MS. received for publication 25. v. 55) 

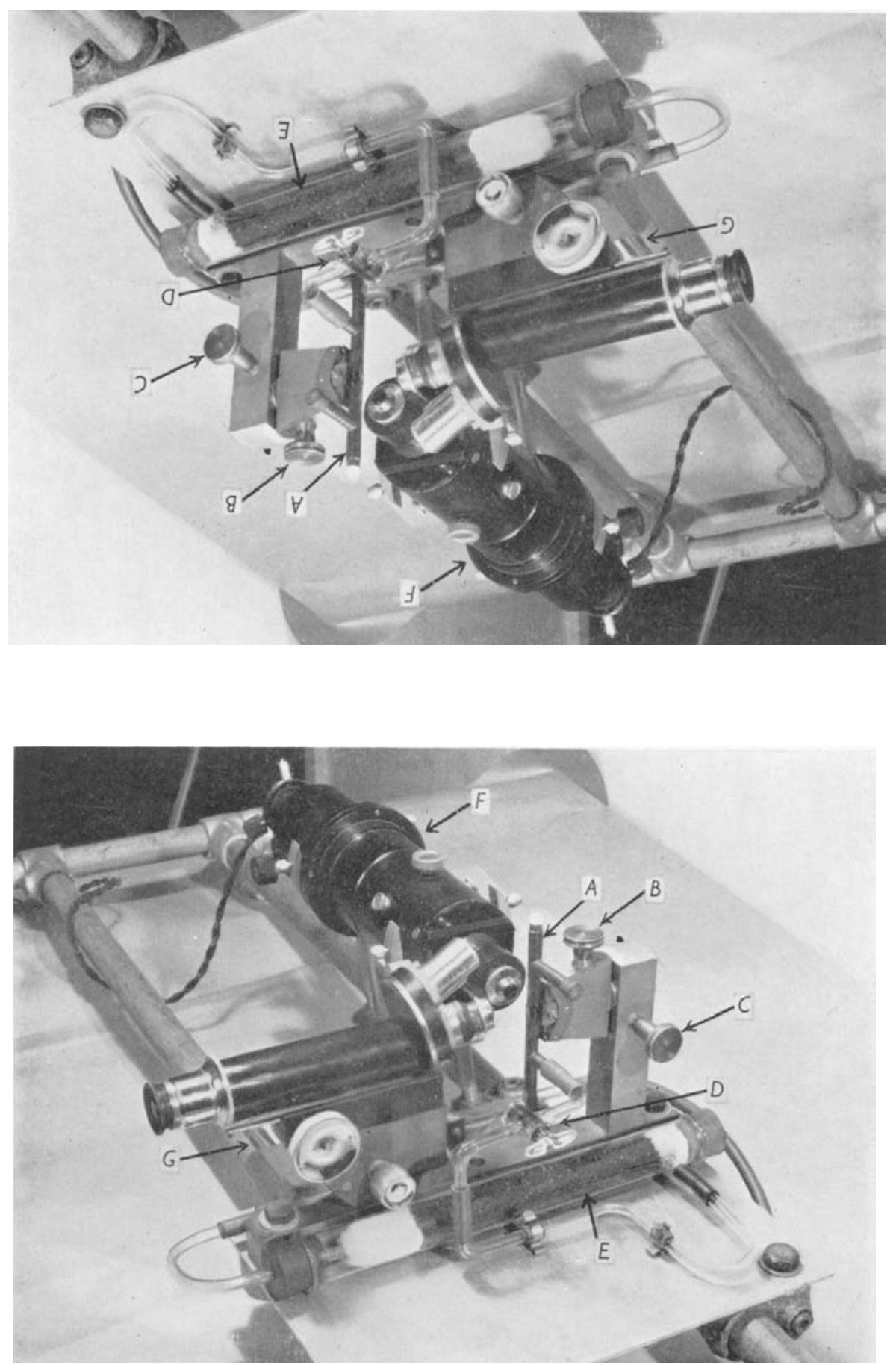
